University of Wollongong

Research Online

Faculty of Science, Medicine and Health -

Papers: Part B

Faculty of Science, Medicine and Health

2020

\title{
Nutritional Status According to the Mini Nutritional Assessment \\ Predicts Speed and Degree of Functional Improvement and Discharge Outcomes in Rehabilitation Patients
}

\author{
Kelly Lambert \\ University of Wollongong, klambert@uow.edu.au \\ Emily Taylor \\ University of Wollongong \\ Steven Bowden \\ Sutherland Hospital \\ Karen E. Charlton \\ University of Wollongong, karenc@uow.edu.au
}

Follow this and additional works at: https://ro.uow.edu.au/smhpapers1

Publication Details Citation

Lambert, K., Taylor, E., Bowden, S., \& Charlton, K. E. (2020). Nutritional Status According to the Mini Nutritional Assessment Predicts Speed and Degree of Functional Improvement and Discharge Outcomes in Rehabilitation Patients. Faculty of Science, Medicine and Health - Papers: Part B. Retrieved from https://ro.uow.edu.au/smhpapers1/1080

Research Online is the open access institutional repository for the University of Wollongong. For further information contact the UOW Library: research-pubs@uow.edu.au 


\title{
Nutritional Status According to the Mini Nutritional Assessment Predicts Speed and Degree of Functional Improvement and Discharge Outcomes in Rehabilitation Patients
}

\author{
Abstract \\ This retrospective observational study evaluated the association between nutritional status, functional \\ ability and discharge outcomes. Data from 1430 older rehabilitation patients (43\% male, median age 79 \\ years, interquartile range: $74-84)$ were analyzed. One fifth $(20.6 \%, n=294)$ of patients were malnourished \\ on admission to rehabilitation. Three important findings were evident. Firstly, nutritional status on \\ admission to rehabilitation was associated with reduced functional, motor, cognitive and feeding scores \\ on admission and discharge (all $P<0.05$ ). Secondly, malnutrition at admission was associated with \\ significantly slower gains in rehabilitation. Finally, malnutrition at admission was associated with \\ significantly higher odds of a decline in functional ability during admission (OR 3.95; 95\% Cl: 2.14-7.27), \\ and almost three times greater odds of additional care requirements on discharge (OR: 2.9 ((95\% Cl: \\ 1.02-8.3). The nutritional status of patients on admission to inpatient rehabilitation is a predictor of both \\ the speed and degree of rehabilitation gains and discharge outcomes.

\section{Publication Details} \\ Lambert, K., Taylor, E., Bowden, S. \& Charlton, K. (2020). Nutritional Status According to the Mini \\ Nutritional Assessment Predicts Speed and Degree of Functional Improvement and Discharge Outcomes \\ in Rehabilitation Patients. Journal of Nutrition in Gerontology and Geriatrics, 39 (1), 16-29.
}




\section{Title page}

2 Title: Nutritional status according to the Mini Nutritional Assessment predicts

3 speed and degree of functional improvement and discharge outcomes in

4 rehabilitation patients

5 Kelly Lambert ${ }^{a *}$, Emily Taylor ${ }^{a}$, Steven Bowden ${ }^{b}$ and Karen Charlton ${ }^{a}$

$6 \quad{ }^{a}$ Discipline of Nutrition and Dietetics, School of Medicine, Faculty of Science,

7 Medicine and Health, University of Wollongong, Wollongong, New South Wales,

8 Australia

$9{ }^{\mathrm{b}}$ Healthcare Improvement Analytics, Sutherland Hospital, New South Wales, Australia,

$10 *$ Corresponding Author: Discipline of Nutrition and Dietetics, School of Medicine,

11 Faculty of Science, Medicine and Health, University of Wollongong, Wollongong, New

12 South Wales, Australia 2522 Email: klambert@uow.edu.au

13 
1 Title: Nutritional status according to the Mini Nutritional Assessment

2 predicts speed and degree of functional improvement and discharge

3 outcomes in rehabilitation patients

4 Abstract:

5

6

This retrospective observational study evaluated the association between nutritional status, functional ability and discharge outcomes. Data from 1430 elderly rehabilitation patients ( $43 \%$ male, median age 79 years, interquartile range: 74 to 84$)$ were analysed. One fifth $(20.6 \%, n=294)$ of patients were malnourished on admission to rehabilitation. Three important findings were evident. Firstly, nutritional status on admission to rehabilitation was associated with reduced functional, motor, cognitive and feeding scores on admission and discharge (all $\mathrm{p}<0.05$ ). Secondly, malnutrition at admission was associated with significantly slower gains in rehabilitation. Finally, malnutrition at admission was associated with significantly higher odds of a decline in functional ability during admission (OR 3.95; 95\% CI:2.14-7.27), and almost three times greater odds of additional care requirements on discharge (OR: 2.9 ((95\% CI:1.02-8.3). The nutritional status of patients on admission to inpatient rehabilitation is a predictor of both the speed and degree of rehabilitation gains and discharge outcomes.

Keywords: nutritional status; physical function, hospital-discharged; health outcomes, malnutrition; rehabilitation; observational retrospective study

\section{Introduction}

Rehabilitation services and programs aim to help a patient recover and/or adapt from an injury or illness. According to the World Health Organisation (1), the goal of a 
1 rehabilitation programme may be to improve self-care, mobility, functional

2 independence, social participation, education, or return to work. To achieve these goals,

3 rehabilitation personnel develop treatment plans based on a series of assessments of the

4 patient and their environment. Two of these assessments include evaluation of an

5 individual's nutritional status, and evaluation of their physical capability and level of

6 independence in the activities of daily living (2).

7

8 Malnutrition is a major concern in the health system, as the effects are costly and far-

9 reaching (3). In the rehabilitation health care setting, the prevalence of malnutrition

10 ranges between 30 and $50 \%$ (4). Malnutrition has been found to increase morbidity,

11 mortality, and the incidence of complications (5). Furthermore, these effects can lead to

12 increased treatment costs, length of stay, and admission to a higher level of care (5).

13 Hence, it is necessary to accurately identify, manage, and monitor malnutrition in order

14 for patient outcomes to be improved (6). Nutritional assessment tools enable a registered

15 dietitian, or medical staff, to make a diagnosis of malnutrition (7). Two tools that have

16 been validated for the rehabilitation setting (8) include the Mini Nutritional Assessment

17 (MNA)(9) and the Subjective Global Assessment (SGA)(10).

19 In addition to nutritional status, functional ability is assessed as an outcome indicator of

20 progress in patients in rehabilitation settings (11). The ability to perform activities of

21 daily living indicates functional status and the Functional Independence Measure (FIM)

22 is used to provide a basic indicator of the severity of disability. The tool is used to track

23 changes in a patient's functional ability during a rehabilitation episode (11). 
1 The extent to which the conditions malnutrition and reduced functional ability coexist has

2 not been extensively researched. This study therefore aims to determine the association

3 between nutritional status; as measured by the MNA; and functional status; as measured

4 by the FIM; in a large population of Australian rehabilitation patients. The secondary

5 objective is to explore the strength of any relationship between malnutrition and

6 functional impairment sub categories, length of stay, impairment type and discharge

7 destination after adjustment for key covariates.

$9 \quad$ Materials and method

10 This was an observational retrospective study. Data was analysed from all patients

11 admitted to one of three dedicated rehabilitation wards within one local health district

12 [removed for peer review] between July 2010 and June 2013. Two of the rehabilitation

13 wards were at one hospital site, while the third ward was at another location within the

14 same health district. All patients were evaluated by the same rehabilitation physician as

15 to their suitability for admission to rehabilitation. The location of ward admission was

16 dictated by the proximity of the ward to the patient's home address. Each rehabilitation

17 ward consists of a 20-22 inpatient bed ward staffed by a range of health professional

18 staff including rehabilitation physicians, nurses, dietitians, physical therapists, speech

19 pathology, occupation therapists and social workers. FIM scores are completed by

20 trained staff, usually the occupational therapist or nurse on admission and discharge. 
1 Ethical approval for this study was obtained from the University of [removed for peer

2 review] Human Research Ethics Committee (HE16/213).

4 Functional ability was assessed using the 18-item FIM tool. The FIM tool has been 5 demonstrated to be a valid tool in the geriatric rehabilitation population $(12,13)$, with high

6 interrater reliability $(14,15)$. The items in the FIM are divided into two groups: 5 cognitive 7 items and 13 motor items (including feeding status). Each item is assessed against a seven 8 point ordinal scale, where the higher the score indicates greater independence to perform 9 the activity assessed by the item. (11) The highest score achievable is 126 and lowest 18 10 (indicating complete dependence on others for all activities of daily living). The FIM is 11 completed by nursing staff in conjunction with physiotherapy and occupational therapy 12 staff on admission and discharge. FIM gain was also investigated in this study, which is 13 the change in total FIM score from admission to discharge, and FIM efficiency, which is 14 FIM gain divided by length of stay. FIM efficiency indicates the rate of functional improvement and is expressed as points per day. The outcomes of interest in this study were FIM gain and FIM efficiency, as well as total FIM score, and the subdomains of

17 motor FIM score, cognitive FIM score, and feeding ability FIM score. The FIM data was 18 extracted from the health district wide rehabilitation database (Synaptix Database). This

19 software system records all episodic data relating to all admissions to rehabilitation in the health district.

22 The MNA tool was used to assess nutritional status (9). The MNA is a validated,

23 reliable nutrition assessment tool specifically designed for older adults aged $65 \mathrm{y}$ and

24 older(16-18). The MNA is an 18-item questionnaire, consisting of six questions that 
1 are primarily used as a screening tool (maximum score of 14 points), and twelve

2 questions (items $\mathrm{G}$ to $\mathrm{R}$ ), which are used in addition to fully assess a patient for the

3 presence of, or risk of, malnutrition (maximum possible score of 30 points). Nutritional

4 status is categorised as follows: Malnourished ( $<17$ points), At Risk of Malnutrition (17

5 to 23.5 points), and Well Nourished status $(\geq 24)$. In this study, the association between

6 MNA items B (weight loss) and E (neuropsychological problems) and FIM scores were

7 also explored. At the time, of the study all patients admitted to rehabilitation had an

8 MNA completed by the ward dietitian as part of routine clinical care. Interrater

9 reliability of the MNA tool is known to be high $(>90 \%)(19,20)$ and the MNA is used

10 routinely in the health district where the study occurred as a nutrition assessment tool by

11 the dietitians for all geriatric patients (those $>65$ years old). MNA data was obtained

12 from the [health district name removed] Nutrition Department Rehabilitation

13 Assessment Database.

14 Demographic and clinical variables such as age, gender, and length of rehabilitation

15 stay were obtained from internal ministry of health databases (the Synaptix Database).

16 This included intended and actual discharge location, which are recorded by admitting

17 hospital staff (usually the occupational therapist or nurse). For the purposes of this study

18 the dependent variable of discharge location was created by comparing intended

19 discharge location with actual discharge location. Scores were then aggregated into one

20 of three groups: no change in the level of care on discharge; a decrease in the level of

21 care on discharge; and an increase in the level of care on discharge.

23 Statistical analysis was performed using the SPSS (version 21, 2012, IBM Corporation).

24 The Shapiro Wilk test was used to ascertain normality of continuous data. Parametric data

25 were reported as the mean \pm standard deviation, and nonparametric data were reported as 
1 the median and interquartile range. One-way analysis of variance was performed to

2 analyse the relationship between FIM efficiency and the three nutrition status categories

3 (Well Nourished, At Risk of Malnutrition and Malnourished). The Kruskal Wallis test

4 was used to determine differences in FIM score between nutritional status catgories.

5 Spearman's correlation was used to analyse the strength of association among the four

6 MNA components (total MNA screen score; MNA part B score; MNA part E score; and

7 total MNA score) with the FIM scores at admission and discharge (total FIM score;

8 feeding FIM score; cognitive FIM score; and motor FIM score). The strength of the

9 association was evaluated using a rho of $\leq 0.30$ as a weak association; 0.3-0.5 as a

10 moderately strong association; and $>0.5$ as a strong association (21). Chi squared tests

11 were performed to ascertain the association between nutritional status and change in FIM

12 scores. Binary logistic regression models were used to explore the relationship between

13 nutritional status and outcomes such as FIM score, length of hospital stay, and care needs

14 after discharge. Analyses were adjusted for age, gender and length of stay. Length of stay

15 was included as a binary rather than continuous variable and the median length of stay

16 for the cohort of 21 days was selected as the cut off (ie less than 21 days or not). Multiple

17 linear regression analysis was used to test if the MNA score significantly predicted

18 discharge FIM scores, subcomponent scores, and FIM efficiency scores after controlling

19 for age and LOS. A p value of $<0.05$ was considered statistically significant.

\section{Results}

22 A total of 1530 patients were included on the Nutrition Department Rehabilitation

23 Assessment Database. Of these 7.6\% (117) did not contain length of stay, discharge

24 outcome or other data (such as all FIM score components or details of admission

25 diagnosis). This left a total of 1430 patients eligible for analysis. Table 1 shows the 
1 demographic and clinical characteristics of the patients included in the study. Of the 1430

2 elderly rehabilitation patients $(42.7 \%$ male), the median age was 79 years (interquartile

3 range IQR: $74-84 \mathrm{y})$. Approximately one fifth of individuals $(20.6 \%, \mathrm{n}=294)$ were

4 classified as malnourished, $53 \%$ were at risk of malnutrition $(n=763)$, and 372 were well

5 nourished (26.1\%) according to the MNA score.

6

7 LOS was significantly different between nutritional status categories, with the MN group

8 having the longest LOS after adjustment (median 26 days, Interquartile Range 15-39

9 days, $\mathrm{p}<0.0001$ ). The FIM scores on hospital admission were also significantly lower for

10 malnourished individuals. The Malnourished group had the lowest FIM scores on

11 admission (median 65, IQR: 48-80, $<<0.0001$ ), and the lowest motor FIM, cognitive FIM

12 and feeding FIM scores on admission (all $\mathrm{p}<0.0001$ ). The Malnourished group had a

13 significantly greater proportion of patients with a pulmonary diagnosis or were classified

14 as for reconditioning compared to the Well Nourished or At Risk groups $(\mathrm{p}<0.0001)$.

16 The strength and direction of the association between nutritional status and FIM scores

17 on admission and discharge are shown in Table 2. Overall there was a moderately strong

18 positive association between nutritional status and functional status (including total,

19 feeding and motor subdomains) on discharge. The association between MNA score on

20 admission and the total FIM and motor FIM scores on admission were also moderately

21 strong (total FIM score $r_{s}=0.34, \mathrm{p}<0.01$; motor FIM score on admission $r_{s}=0.33$,

$22 \mathrm{p}<0.01)$. The association between MNA Part B and functional status was a positive weak

23 one and not statistically significant. The only association significant association between

24 MNA Part E and functional status was for motor FIM score on admission $\left(r_{s}=0.33\right.$, $25 \mathrm{p}<0.01)$. 
2 Table 3 shows the difference between each nutrition category for FIM gain, FIM

3 efficiency, and FIM scores at discharge. The discharge outcome is recorded as either a

4 level of care better or the same as on admission or worse than admission. There were

5 significant differences between FIM scores at discharge according to nutritional status.

6 In each FIM subscore component, malnourished individuals on admission had lower FIM

7 scores on discharge ( $p<0.0001$ for all FIM score components). More importantly, FIM

8 gain scores were also lowest in the malnourished group $(\mathrm{p}=0.0004)$. Similarly, those in

9 the malnourished group had a significantly smaller gain in FIM score (8.4\% compared to

$109.9 \%$ gain in the at risk group and $14.1 \%$ gain in the well-nourished group, $p=0.008$ ).

11 This concept of the MCID for nutritional status warrants further investigation.

13 Table 3 also displays FIM efficiency scores. Well-nourished patients had greater FIM

14 efficiency than poorly nourished counterparts for total FIM score and the domains of 15 motor, cognitive and feeding FIM efficiency $(p<0.0001, p<0.0001, p=0.03$ and $p=0.03$ 16 respectively). The Malnourished group had a negative mean cognitive FIM efficiency 17 (mean efficiency per day: $-0.01,95 \%$ CI: $0.03-0.06, p=0.03$ ) (indicating they lost FIM 18 points over time) and had a neutral mean feeding FIM efficiency (mean efficiency per 19 day: 0.00, 95\% CI: -0.01-0.02, $\mathrm{p}=0.03$ ), indicating no improvement in feeding FIM over 20 the length of stay.

22 Table 4 reports the results of multiple linear regression analyses to determine if MNA 23 score significantly predicted discharge FIM scores, subcomponent scores, and FIM 24 efficiency scores after controlling for age and LOS. The results in all models were 25 significant except for cognitive FIM efficiency. MNA score accounted for $16 \%$ of the 
1 variance in total discharge FIM score and resulted in a 2.1-point increase in discharge

2 total FIM score for every 1 unit increase in the MNA score on admission.

3

4 Logistic regression analysis showed that individuals who were malnourished or at risk of

5 malnutrition were nearly twice as likely to have a length of stay longer than 21 days (OR:

6 1.84, CI: 1.45 - 2.34) (Table 5). These individuals were also more likely to experience a

7 reduction in total FIM score (OR: 3.95, CI: 2.14-7.27)). Malnutrition was also associated

8 with an increase in the level of care required on discharge (OR: 2.9, CI: $1.02-8.3$, Table

9 5); a worse motor FIM (OR: 3.27, CI: 1.84-5.8), and feeding FIM (OR: 3.21, CI: 1.52-

10 8.81) on discharge, but not cognitive FIM (Table 5).

\section{Discussion}

13 This retrospective analysis of 1430 older patients that had been admitted to rehabilitation

14 hospitals in regional New South Wales, Australia between 2010 and 2013 found that

15 nutritional status at hospital admission predicted functional status on admission as well

16 as improvement in functional ability during their hospital stay. Patients who were well-

17 nourished had a significantly greater gain in FIM scores than their malnourished

18 counterparts while those that were malnourished or at risk of malnutrition were

19 significantly more likely to have a decrease in both total and motor FIM scores.

21 This finding agrees with several previous studies. For example, Nishioka et al reported

22 that FIM gain was significantly higher in patients who had the greatest improvement in nutritional status, compared to those with no improvement in their nutritional status (22).

24 Schrader et al. similarly showed that functional ability scores decreased with the 25 deterioration of nutritional status (23). In contrast, Nii et al. did not find a difference in 
1 functional performance between malnourished and at-risk of malnutrition patients, but

2 reported that well-nourished patients had a significantly higher cognitive score (24). The

3 present study strengthens the evidence base regarding improvements during rehabilitation

4 as previous studies were restricted to small datasets $(<200$ patients $)$ or were limited to

5 specific subtypes of rehabilitation patients (such as stroke or only acute geriatric patients).

6

7 Our study also found that malnourished patients were between 3 and 4 times more likely

8 to have a reduction in the total FIM score, as well as motor and feeding sub-domains.

9 Moreover, even being at risk of malnutrition significantly increased how likely an

10 individual was to have a reduction in their total and motor FIM scores. Those with a

11 hospital stay of longer than 21 days were almost twice as likely to be malnourished or at

12 risk of malnutrition compared to those with shorter stays. Similarly, a study of stroke

13 patients in rehabilitation, Finestone et al. found that the Modified Barthel Index scores (a

14 test similar to the FIM, that assesses activities of daily living) were highly predictive of

15 length of stay and also that malnutrition was related to lower Modified Barthel Index

16 scores) (25). More recently this relationship between malnutrition and functional status

17 on discharge was also described in several smaller cohorts of patients on discharge from

18 acute care $(26,27)$.

20 The focus of this study was primarily on exploring the association between nutritional 21 status score and functional ability in the rehabilitation setting. The main outcomes 22 measured in this study were the association between FIM sub-domains and MNA sub23 domains, the FIM gain (the change in FIM score from admission to discharge), and the 24 FIM efficiency (the FIM gain divided by length of stay). FIM efficiency is a metric that 25 considers rate of functional improvement according to patient's length of stay. The 
1 current study found that well-nourished patients had the greatest total FIM score

2 efficiency, while malnourished patients had the smallest. This finding was consistent

3 across sub-domains of the FIM score (motor, feeding, cognitive). Finestone et al. found

4 that well-nourished patients had a significantly better rate of functional improvement than

5 that of the malnourished patients (25) at the time of discharge well-nourished and

6 malnourished patients had improved in functional ability to a similar level, but that well-

7 nourished patients had accomplished this in significantly less time. (25). Similarly, recent

8 work by Tanaka et al found that FIM efficacy was also related to nutritional status in a

9 small cohort of Japanese patients admitted for rehabilitation due to spinal cord injury (28).

10 Our study further describes this relationship by outlining where the FIM efficiency gains

11 may be made. For example, we identified a decline in cognitive ability in patients that

12 were malnourished over their rehabilitation stay, while feeding ability did not change over

13 rehabilitation.

15 Few studies in the geriatric rehabilitation literature have used datasets as large as ours to 16 explore the relationship between nutritional status and outcomes during and after 17 rehabilitation. While this is an important strength, there were several limitations with this 18 study. First, only one MNA was performed, at hospital admission, therefore the extent to 19 which a patient's nutritional status changed during rehabilitation could not be described.

20 Previous studies have suggested that malnutrition is highly prevalent in the rehabilitation 21 setting, from $30 \%$ to $50 \%$ (10). This study had a lower prevalence of malnutrition, at $2220.6 \%$, however over half the population were at risk of malnutrition $(53.4 \%)$, which is 23 consistent with previous studies published by our research group $(17,29)$. The 24 observational nature of the study design cannot rule out unmeasured confounding. 25 Secondly, some patients were excluded due to a lack of necessary information meant that 
1 some selection bias could have been present. Further studies are therefore necessary in

2 rehabilitation settings to explore the relationship between changes in nutritional status

3 and its influence on functional recovery. Additional exploration is also warranted

4 investigating the minimal clinically important difference for the MNA. No studies appear

5 to have investigated this point and would be useful for clinicians.

6

7 This secondary analysis of data on older patients admitted to a rehabilitation hospital has

8 demonstrated that malnutrition is modestly associated with reduced functional ability

9 during their hospital rehabilitation stay. Malnourished patients also demonstrate slower

10 gains in functional ability and have increased care needs on discharge, compared to their

11 peers that were well-nourished or those classified as being at risk of malnutrition. The

12 finding that a 1 unit increase in MNA score on admission results in a 2.1 unit increase in

13 FIM score on discharge has important implications for clinicians. For example, improving

14 the nutritional status of a patient to result in a change from malnourished to at risk

15 category could result in a potential gain of more than 13 points on the FIM score. This is

16 substantially more than the 3 point minimal clinically important difference cited in other

17 studies. This data reinforces the need for nutrition screening in acute care, close

18 monitoring of nutritional intake and nutritional status during hospital admission and for

19 targeted nutritional interventions prior to and during rehabilitation (to improve/prevent

20 decline) to optimise the functional recovery of patients.

22 Take away points

23 - The relationship between nutritional status and rehabilitation outcomes has been

24 described in many studies. However, these studies are often small or restricted to

25 specific subtypes of rehabilitation patients. 
- This retrospective observational study evaluated the association between nutritional status, functional ability and discharge outcomes in a large data set of 1430 elderly rehabilitation patients in one health district.

- One fifth $(20.6 \%, \mathrm{n}=294)$ of patients were malnourished and $53 \%$ were at risk of malnutrition $(\mathrm{n}=763)$ on admission to rehabilitation.

- Nutritional status on admission was modestly associated with reduced functional, motor, cognitive and feeding ability on admission and discharge (all $\mathrm{p}<0.05$ ).

- Malnutrition was associated with significantly slower gains in rehabilitation and significantly higher odds of a decline in functional ability during the admission (OR 3.95; 95\% CI:2.14-7.27), and almost three times greater odds of additional care requirements on discharge (OR: 2.9 ((95\% CI:1.02-8.3).

- The nutritional status of patients on admission to inpatient rehabilitation is a predictor of both the speed and degree of rehabilitation gains and discharge outcomes.

- The finding that a 1 unit increase in MNA score on admission results in a 2.1 unit increase in FIM score on discharge reinforces the need for close attention to nutritional status in order to optimise rehabilitation potential and discharge outcomes.

Acknowledgements: Thank you to the Department of Clinical Nutrition for assistance with this project.

\section{Declaration of interest statement:}


1 Funding statement: nil funding for this study

2 Contribution of authors: KL: Refinements to study design, data analysis, primary

3 responsibility for writing the article. KC: Refinements to study design, data analysis,

4 writing the article. ET: Data collection and analysis, writing the article. SB:

5 Conceptualisation of study design, assistance with interpretation, writing the article

6 All authors participated in the drafting and approval of the final manuscript submitted

7 for publication.

9 References:

10 1. World Health Organisation. Goals of Rehabilitation 2014 [Available from:

11 http://www.euro.who.int/ data/assets/pdf file/0007/275803/Goals-disability-

12 rehabilitation set-of-3-posters Eng LLV.pdf.

132 2. Stott DJ, Quinn TJ. Principles of rehabilitation of older people. Medicine.

$142017 ; 45(1): 1-5$.

$153 . \quad$ Curtis LJ, Bernier P, Jeejeebhoy K, Allard J, Duerksen D, Gramlich L, et al.

16 Costs of hospital malnutrition. Clinical Nutrition. 2017;36(5):1391-6.

17 4. Field LB HR. Differentiating Malnutrition Screening and Assessment: A

18 Nutrition Care Process Perspective. Journal of the Academy of Nutrition and Dietetics.

$192015 ; 115(5): 824-8$.

20 5. Marshall S, Bauer J, Isenring E. The consequences of malnutrition following

21 discharge from rehabilitation to the community: a systematic review of current evidence

22 in older adults. Journal of Human Nutrition and Dietetics. 2014;27(2):133-41.

23 6. Lacey K, Pritchett E. Nutrition Care Process and Model: ADA adopts road map

24 to quality care and outcomes management. Journal of the American Dietetic

25 Association. 2003;103(8):1061-72.

26 7. Field LB, Hand RK. Differentiating Malnutrition Screening and Assessment: A

27 Nutrition Care Process Perspective. Journal of the Academy of Nutrition and Dietetics.

$28 \quad 2015 ; 115(5): 824-8$.

29 8. Marshall S, Young A, Bauer J, Isenring E. Nutrition Screening in Geriatric

30 Rehabilitation: Criterion (Concurrent and Predictive) Validity of the Malnutrition

31 Screening Tool and the Mini Nutritional Assessment-Short Form. Journal of the

32 Academy of Nutrition and Dietetics. 2016;116(5):795-801.

33 9. Guigoz Y. The Mini Nutritional Assessment (MNA) review of the literature--

34 What does it tell us? J Nutr Health Aging. 2006;10(6):466-85; discussion 85-7.

35 10. Watterson C, Fraser A, Banks M, Isenring E, Miller M, Silvester C, et al.

36 Evidence based practice guidelines for the nutritional management of malnutrition in

37 adult patients across the continuum of care. Nutrition \& Dietetics. 2009;66:S1-34.

38 11. Cournan M. Use of the functional independence measure for outcomes

39 measurement in acute inpatient rehabilitation. Rehabilitation Nursing. 2011;36(3). 
12. Kidd D, Stewart G, Baldry J, Johnson J, Rossiter D, Petruckevitch A, et al. The Functional Independence Measure: a comparative validity and reliability study. Disabil Rehabil. 1995;17(1):10-4.

4 13. Pollak N, Rheault W, Stoecker JL. Reliability and validity of the FIM for

5 persons aged 80 years and above from a multilevel continuing care retirement

6 community. Arch Phys Med Rehabil. 1996;77(10):1056-61.

7 14. Ottenbacher KJ, Hsu Y, Granger CV, Fiedler RC. The reliability of the

8 functional independence measure: a quantitative review. Arch Phys Med Rehabil.

9 1996;77(12):1226-32.

10 15. Hamilton BB, Laughlin JA, Fiedler RC, Granger CV. Interrater reliability of the

11 7-level functional independence measure (FIM). Scand J Rehabil Med. 1994;26(3):115129.

13 16. Barone L, Milosavljevic M, Gazibarich BJJONH, AGING. Assessing the older 14 person: is the MNA a more appropriate nutritional assessment tool than the SGA? 15 2003;7(1):13-7.

16 17. Charlton KE, Nichols C, Bowden S, Lambert K, Barone L, Mason M, et al. 17 Older rehabilitation patients are at high risk of malnutrition: evidence from a large

18 Australian database. The journal of nutrition, health \& aging. 2010;14(8):622-8.

19 18. Tsai AC, Wang J-Y, Chang T-L, Li T-Y. A comparison of the full Mini

20 Nutritional Assessment, short-form Mini Nutritional Assessment, and Subjective Global

21 Assessment to predict the risk of protein-energy malnutrition in patients on peritoneal 22 dialysis: A cross-sectional study. Int J Nurs Stud. 2013;50(1):83-9.

23 19. Wikby K, Ek A-C, Christensson L. The two-step Mini Nutritional Assessment 24 procedure in community resident homes. 2008;17(9):1211-8.

25 20. Neumann S.A. MMD, Daniels L.A., Ahern M., Crotty M., . Mini Nutritional 26 Assessment in geriatric rehabilitation: Inter-rater reliability and relationship to body 27 composition and nutritional biochemistry. 2007;64(3):179-85.

28 21. Khamis H. Measures of Association: How to Choose? Journal of Diagnostic 29 Medical Sonography. 2008;24(3):155-62.

30 22. Nishioka S, Wakabayashi H, Nishioka E, Yoshida T, Mori N, Watanabe R.

31 Nutritional Improvement Correlates with Recovery of Activities of Daily Living among

32 Malnourished Elderly Stroke Patients in the Convalescent Stage: A Cross-Sectional

33 Study. Journal of the Academy of Nutrition \& Dietetics. 2016;116(5):837-43.

34 23. Schrader E, Baumgärtel C, Gueldenzoph H, Stehle P, Uter W, Sieber CC, et al.

35 Nutritional status according to Mini Nutritional Assessment is related to functional

36 status in geriatric patients--independent of health status. The Journal Of Nutrition,

37 Health \& Aging. 2014;18(3):257-63.

38 24. Nii M, Maeda K, Wakabayashi H, Nishioka S, Tanaka A. Nutritional

39 Improvement and Energy Intake Are Associated with Functional Recovery in Patients

40 after Cerebrovascular Disorders. Journal of Stroke and Cerebrovascular Diseases.

$41 \quad 2016 ; 25: 57-62$.

42 25. Finestone HM, Greene-Finestone LS, Wilson ES, Teasell RW. Prolonged length

43 of stay and reduced functional improvement rate in malnourished stroke rehabilitation

44 patients. Archives of Physical Medicine \& Rehabilitation. 1996;77(4):340-5.

45 26. Maeda K, Koga T, Akagi J. Nutritional variables predict chances of returning

46 home and activities of daily living in post-acute geriatric care. Clin Interv Aging.

$47 \quad 2018 ; 13: 151-7$.

48 27. Nishioka S, Wakabayashi H, Momosaki R. Nutritional Status Changes and

49 Activities of Daily Living after Hip Fracture in Convalescent Rehabilitation Units: A 
1 Retrospective Observational Cohort Study from the Japan Rehabilitation Nutrition

2 Database. Journal of the Academy of Nutrition and Dietetics. 2018;118(7):1270-6.

3 28. Tanaka M, Momosaki R, Wakabayashi H, Kikura T, Maeda K. Relationship

4 between nutritional status and improved ADL in individuals with cervical spinal cord

5 injury in a convalescent rehabilitation ward. Spinal Cord. 2019.

6 29. Charlton KE, Batterham MJ, Bowden S, Ghosh A, Caldwell K, Barone L, et al.

7 A high prevalence of malnutrition in acute geriatric patients predicts adverse clinical

8 outcomes and mortality within 12 months. e-SPEN Journal. 2013;8(3):e120-e5.

9

10 
1 Table 1: Characteristics of 1430 patients aged 65 years or older on admission to 2 rehabilitation.

\begin{tabular}{|c|c|c|c|c|}
\hline Characteristic & $\begin{array}{c}\text { Well Nourished } \\
\mathbf{n = 3 7 2}\end{array}$ & $\begin{array}{c}\text { At Risk of } \\
\text { Malnutrition } \\
n=763\end{array}$ & $\begin{array}{c}\text { Malnourished } \\
\mathbf{n}=\mathbf{2 9 4}\end{array}$ & $P$ value \\
\hline Age (y) Mean $( \pm$ SD) & $78.0( \pm 16.9)$ & $79.3( \pm 7.1)$ & $78.9( \pm 7.3)$ & 0.06 \\
\hline $\begin{array}{l}\text { Gender n (\%) } \\
\text { Male, } \\
\text { Female }\end{array}$ & $\begin{array}{l}145(39.0) \\
228(61.0)\end{array}$ & $\begin{array}{l}326(42.7) \\
437(57.3)\end{array}$ & $\begin{array}{l}140(47.5) \\
154(52.2)\end{array}$ & 0.08 \\
\hline $\begin{array}{l}\text { Length of stay (days) } \\
\text { median (IQR) }\end{array}$ & $18(11-28)$ & $21.5(14-35)$ & $26(15-39)$ & $\mathrm{P}<0.0001$ \\
\hline $\begin{array}{l}\text { FIM on admission } \\
\text { median (IQR) } \\
\text { Total FIM (tFIM) } \\
\text { Motor FIM } \\
\text { Cognitive FIM } \\
\text { Feeding FIM } \\
\end{array}$ & $\begin{array}{c}86(73-97) \\
58(48-67) \\
27(23-31) \\
6(5-7) \\
\end{array}$ & $\begin{array}{c}76(62-89) \\
52(39-61) \\
25(20-30) \\
6(5-7) \\
\end{array}$ & $\begin{array}{c}65(48-80) \\
43(28-56) \\
23(17-28) \\
5(5-6) \\
\end{array}$ & $\begin{array}{l}\mathrm{P}<0.0001 \\
\mathrm{P}<0.0001 \\
\mathrm{P}<0.0001 \\
\mathrm{P}<0.0001\end{array}$ \\
\hline $\begin{array}{l}\text { Impairment Type n (\%) } \\
\text { Amputation } \\
\text { Arthritis } \\
\text { Brain } \\
\text { Cardiac } \\
\text { Multiple Trauma } \\
\text { Neurological } \\
\text { Orthopedic } \\
\text { Other disabling impairment } \\
\text { Pain } \\
\text { Pulmonary } \\
\text { Reconditioning/Restorative } \\
\text { Spinal Cord } \\
\text { Stroke }\end{array}$ & $\begin{array}{c}4(1.1) \\
4(1.1) \\
4(1.1) \\
5(1.3) \\
0(0.0) \\
16(4.3) \\
182(48.9) \\
0(0.0) \\
23(6.2) \\
1(0.3) \\
61(16.4) \\
4(1.1) \\
68(18.3)\end{array}$ & $\begin{array}{c}31(4.1) \\
8(1.1) \\
20(2.6) \\
14(1.8) \\
1(0.1) \\
22(2.9) \\
280(36.7) \\
2(0.3) \\
36(4.7) \\
5(0.7) \\
184(24.1) \\
12(1.6) \\
148(19.4)\end{array}$ & $\begin{array}{c}11(3.7) \\
3(1.0) \\
6(2.0) \\
5(1.7) \\
0(0) \\
9(3.1) \\
94(31.9) \\
0(0) \\
8(2.7) \\
6(2.0) \\
89(30.2) \\
7(2.4) \\
57(19.3)\end{array}$ & $\mathrm{P}<0.0001$ \\
\hline
\end{tabular}

5

6

7

8

9

10

Range for total FIM score is a minimum of 18 to a maximum of 126.

Chi Square tests used to evaluate differences for categorical data (gender, impairment type). ANOVA used to evaluate differences in age between nutritional status categories.

The Kruskal Wallis test was used to determine differences in FIM score between nutritional status categories. 
1 Table 2: The unadjusted association between nutritional status scores and Functional

2 Independence Measure scores on admission and discharge

3

\begin{tabular}{|l|c|c|c|}
\hline & $\begin{array}{c}\text { Total MNA } \\
\text { score }\end{array}$ & $\begin{array}{c}\text { MNA Part B } \\
\text { (weight loss) }\end{array}$ & $\begin{array}{c}\text { MNA Part E } \\
\text { (neuropsych) }\end{array}$ \\
\hline FIM on admission & & & \\
Total FIM & $0.34^{*}$ & 0.16 & 0.20 \\
Feeding FIM & 0.27 & 0.15 & 0.14 \\
Cognitive FIM & 0.23 & 0.12 & 0.26 \\
Motor FIM & $0.33^{*}$ & 0.15 & $0.33^{*}$ \\
\hline FIM on discharge & & & \\
Total FIM & $0.37^{*}$ & 0.18 & 0.23 \\
Feeding FIM & $0.33^{*}$ & 0.17 & 0.18 \\
Cognitive FIM & 0.26 & 0.14 & 0.29 \\
Motor FIM & $0.37^{*}$ & 0.18 & 0.18 \\
\hline
\end{tabular}

4

5 MNA Part E indicates questions relating to neuropsychological status.

$6 * \mathrm{p}<0.05$

7

8 FIM: Functional Independence Measure

9 
Table 3: Unadjusted Functional Independence Measure (FIM) scores at discharge, FIM gain, FIM efficiency, and discharge outcome according to nutritional status

\begin{tabular}{|c|c|c|c|c|}
\hline Characteristic & $\begin{array}{c}\text { Well Nourished } \\
\quad \mathbf{n}=372\end{array}$ & $\begin{array}{c}\text { At Risk of Malnutrition } \\
n=763\end{array}$ & $\begin{array}{c}\text { Malnourished } \\
n=294\end{array}$ & $P$ value \\
\hline $\begin{array}{l}\text { FIM at discharge } \\
\text { Median (IQR) } \\
\text { total FIM score } \\
\text { motor FIM score } \\
\text { cognitive FIM score } \\
\text { feeding FIM score }\end{array}$ & $\begin{array}{c}107(96-115) \\
78(70-84) \\
30(25-33) \\
6(5-7)\end{array}$ & $\begin{array}{c}98(78-108) \\
71(54-79) \\
27(23-31) \\
6(5-7)\end{array}$ & $\begin{array}{c}83(58-1-2) \\
59(36-75) \\
25(18-30) \\
6(5-7)\end{array}$ & $\begin{array}{l}<0.0001 \\
<0.0001 \\
<0.0001 \\
<0.0001\end{array}$ \\
\hline $\begin{array}{l}\text { FIM gain (points) } \\
\text { Mean }( \pm \mathrm{SD}) \\
\text { Mean change }(\%, 95 \% \mathrm{CI})\end{array}$ & $\begin{array}{c}18.5( \pm 14.7) \\
14.1(11.3-17.0)\end{array}$ & $\begin{array}{c}15.9( \pm 17.0) \\
9.9(8.2-11.5)\end{array}$ & $\begin{array}{c}13.6( \pm 19.7) \\
8.4(6.0-10.8)\end{array}$ & $\begin{array}{c}0.0004 \\
0.008\end{array}$ \\
\hline $\begin{array}{l}\text { FIM efficiency (points/d) } \\
\text { Mean (95\% CI) } \\
\text { total FIM points / day } \\
\text { motor FIM points / day } \\
\text { cognitive FIM points / day } \\
\text { feeding FIM points / day }\end{array}$ & $\begin{array}{l}1.15(0.99-1.29) \\
1.04(0.92-1.16) \\
0.11(0.02-0.15) \\
0.03(0.01-0.04)\end{array}$ & $\begin{array}{l}0.66(0.52-0.80) \\
0.61(0.51-0.72) \\
0.04(0.02-0.09) \\
0.02(0.01-0.02)\end{array}$ & $\begin{array}{c}0.44(0.27-0.6) \\
0.44(0.31-0.57) \\
-0.01(0.03-0.06) \\
0.00(-0.01-0.02) \\
\end{array}$ & $\begin{array}{c}<0.0001 \\
<0.0001 \\
0.03 \\
0.03 \\
\end{array}$ \\
\hline $\begin{array}{l}\text { Discharge Outcome n }(\%) \\
\text { Better / Same } \\
\text { Worse }\end{array}$ & $\begin{array}{l}271(72.9) \\
101(27.1)\end{array}$ & $\begin{array}{l}482(63.2) \\
281(36.8)\end{array}$ & $\begin{array}{l}151(51.2) \\
144(48.8)\end{array}$ & 0.02 \\
\hline
\end{tabular}


1 Table 4. Results of multiple linear regression according to nutritional status (MNA) score. Analyses re adjusted for age and length of stay.

2

\begin{tabular}{|l|c|c|c|c|}
\hline & Beta & Adjusted $\mathrm{R}^{2}$ & $\mathrm{R}^{2}$ & P value \\
\hline Discharge total FIM & 2.10 & 0.16 & 0.16 & $<0.001$ \\
\hline Discharge motor FIM & 1.65 & 0.16 & 0.16 & $<0.001$ \\
\hline Discharge cognitive FIM & 0.44 & 0.08 & 0.08 & $<0.001$ \\
\hline Discharge feeding FIM & 0.10 & 0.12 & 0.11 & $<0.001$ \\
\hline FIM gain & 0.57 & 0.06 & 0.06 & $<0.001$ \\
\hline FIM efficiency & 0.06 & 0.03 & 0.03 & $<0.001$ \\
\hline Motor FIM efficiency & 0.05 & 0.04 & 0.04 & $<0.001$ \\
\hline Cognitive FIM efficiency & 0.009 & 0.003 & 0.005 & 0.06 \\
\hline Feeding FIM efficiency & 0.002 & 0.005 & 0.007 & 0.02 \\
\hline
\end{tabular}


1 Table 5. Predictors of rehabilitation outcomes after controlling for age, gender and length of stay

\begin{tabular}{|l|c|c|c|c|c|c|}
\hline & LOS > 21 days & $\begin{array}{c}\text { Higher level of care } \\
\text { on discharge }\end{array}$ & $\begin{array}{c}\text { Worse total FIM } \\
\text { score on discharge }\end{array}$ & $\begin{array}{c}\text { Worse motor FIM } \\
\text { score on discharge }\end{array}$ & $\begin{array}{c}\text { Worse cognitive } \\
\text { FIM score on } \\
\text { discharge }\end{array}$ & $\begin{array}{c}\text { Worse feeding } \\
\text { FIM score on } \\
\text { discharge }\end{array}$ \\
\hline Age & $1.00(0.99-1.02)$ & $1.02(0.98-1.06)$ & $1.02(0.99-1.05)$ & $1.02(0.99-1.05)$ & $1.04(1.01-1.06)^{*}$ & $1.04(0.99-1.06)$ \\
\hline Length of stay & - & $1.03(1.02-1.04)^{*}$ & $1.69(1.17-2.45)^{*}$ & $0.98(0.97-0.99)^{*}$ & $1.14(0.8-1.61)$ & $0.97(0.96-0.99)^{*}$ \\
\hline Male gender & $1.24(1.01-1.54)^{*}$ & $1.22(0.65-2.9)$ & $0.98(0.97-0.99)^{*}$ & $2.03(1.40-2.94)^{*}$ & $1.00(0.99-1.01)$ & $1.67(1.04-2.7)^{*}$ \\
\hline Malnourished & $1.84(1.45-2.34)^{*}$ & $2.9(1.02-8.3)^{*}$ & $3.95(2.14-7.27)^{*}$ & $3.27(1.84-5.8)^{*}$ & $1.51(0.97-2.35)$ & $3.21(1.52-8.81)^{*}$ \\
\hline
\end{tabular}

2

3 Figures represent Adjusted Odds Ratio and 95\% confidence interval;

4 Abbreviations: LOS: length of stay; $* \mathrm{p}<0.05$ 